\title{
Mecanismos celulares e moleculares que controlam o desenvolvimento e o crescimento muscular
}

\author{
Maeli Dal Pai Silva ${ }^{1}$ e Robson Francisco Carvalho ${ }^{2}$
}

1 - Profa. Adjunto do Depto de Morfologia, IB, UNESP, Botucatu, SP. email: dpsilva@ibb.unesp.br

2 - Prof. Dr. do Departamento de Morfologia, IB, UNESP, Botucatu, SP.

RESUMO - O músculo estriado esquelético é formado pela associação de fibras musculares com a matriz extracelular. Esse tecido possui alta plasticidade e o conhecimento das características morfológicas, da mio-gênese, e da dinâmica do crescimento é importante para o entendimento da morfofisiologia bem como para a seleção de animais visando a melhoria na produção de carne. A maioria dos músculos estriados originam-se de células precursoras do mesoderma a partir dos somitos do embrião e o controle da diferenciação ocor-re pela ação de fatores indutores ou inibidores. Um grupo de fatores transcricionais, pertencentes à família MyoD tem um papel central na diferenciação muscular. Coletivamente chamados de Fatores de Regulação Miogênica (MRFs), são conhecidos quatro tipos: MyoD, myf-5, miogenina e MRF4 Esses fatores ligam-se à seqüências de DNA conhecidas como Ebox (CANNTG) na região promotora de vários genes músculo-específicos, levando à expressão dos mesmos. As células embrionárias com potencial para diferenciação em células musculares (células precursoras miogênicas) expressam MyoD e Myf-5 e são denominadas de mioblastos. Essas células proliferam, saem do ciclo celular, expressam miogenina e MRF4, que regulam a fusão e a diferenciação da fibra muscular. Uma população de mioblastos que se diferencia mais tardiamente, as células miossatélites, são responsáveis pelo crescimento muscular no período pós natal, que pode ocorrer por hiperplasia e hipertrofia das fibras. As células satélites quiescentes não expressam os MRFs, porém, sob a ação de estímulos como fatores de crescimento ou citocinas, ocorre a ativação desse tipo celular que prolifera e expressa os MRFs de maneira similar ao que ocorre com as células precursoras miogênicas durante a miogênese. Os mecanismos de crescimento muscular são regulados pela expressão temporal dos (MRFs), que controlam a expressão dos genes relacionados com o crescimento muscular.

Palavras-chave: crescimento e desenvolvimento muscular, fatores reguladores miogênicos, músculo esquelético

\section{Cellular and molecular mechanisms that control muscular development and growth}

\begin{abstract}
Skeletal muscle consists predominantly of muscle fibers surrounded by a connective tissue layer. This tissue has a great plasticity, and the knowledge of the morphological characteristics, myogenesis, and growth dynamics is important to the understanding of its physiology and to the farm animal selection for meat production. Most skeletal muscles are derived from mesodermal precursor cells originated from the somites. During embryonic development, specification of mesodermal precursor cells to the myogenic lineage is regulated by positive and negative signals from surrounding tissues. Specification to the myogenic lineage requires the up-regulation of four muscle-specific transcriptional factors (MyoD, Myf5, myogenin, and MRF4), called myogenic regulatory factors (MRFs), which have a well-defined role in skeletal muscle development and differentiation. The MRFs belong to the basic helix-loop-helix (bHLH) super family of transcription factors, that forms heterodimers and bind to the E-box (CANNTG) DNA sequence motif found in the promoters of many muscle specific genes. Specification to the myogenic lineage requires the upregulation of the MRFs MyoD and Myf5. Proliferative MyoD and/or Myf5 positive myogenic cells are termed myoblasts. Proliferating myoblasts withdraw from the cell cycle to become terminally differentiated myocytes that express the "late" MRFs, myogenin and MRF4. Specialized populations of myogenic stem cells, termed satellite cells, arise during the late stages of embryogenesis are highly active during the postnatal muscle growth, which may occur by muscle fiber hyperplasia or hypertrophy. Quiescent satellite cells do not express detectable levels of MRF; however, during muscle growth, in response to several growth factors, activated satellite cells proliferate and express the MRFs in a similar manner to muscle precursor cells during skeletal muscle development. Muscle growth mechanisms are controlled by the temporally expression of muscle growth related genes induced by the MRFs.
\end{abstract}

Key Words: muscle development and growth, myogenic regulatory factors, skeletal muscle

Correspondências devem ser enviadas para: dpsilva@ibb.unesp.br 


\section{Características das fibras musculares estriadas esqueléticas adultas}

O músculo estriado esquelético está envolvido com a locomoção, postura, com os movimentos de respiração e forma o maior tecido constituinte do corpo dos vertebrados. É constituído por células que possuem capacidade contrátil, uma propriedade fundamental de todas as células animais, e que alcança sua maior expressão nas células musculares. Como as células musculares estriadas são alongadas e estreitas, são denominadas de fibras musculares estriadas.

As fibras musculares estriadas esqueléticas são multinucleadas e os núcleos estão localizados na região periférica da fibra, abaixo da membrana plasmática. O diâmetro das fibras varia, em média, de 10 a $100 \mu \mathrm{m}$ e o comprimento pode chegar até $10 \mathrm{~cm}$, sendo variável, na dependência da arquitetura do músculo. O sarcoplasma possui um citoesqueleto altamente desenvolvido, constituído principalmente por miofibrilas que se estendem por todo o comprimento da fibra (Figura 1).

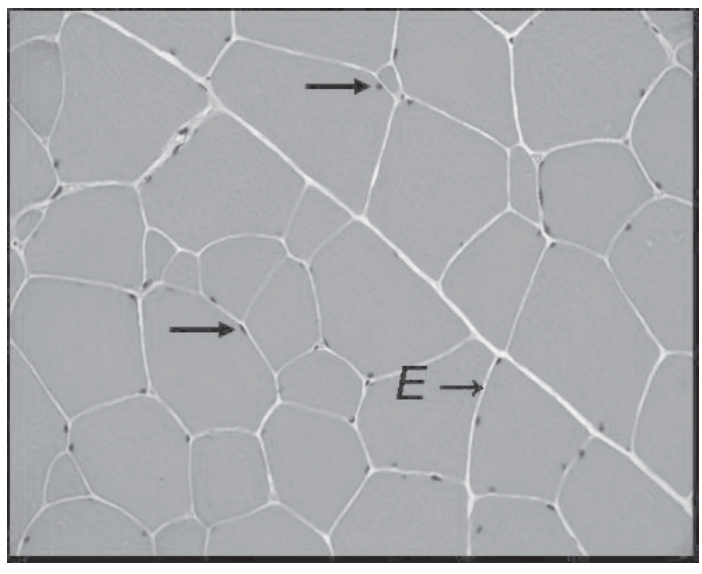

Figura 1 - Fotomicrografia de corte transversal de fibras do músculo Extensor Longo dos Dedos de rato. Núcleos localizados na periferia das fibras (setas). Endomísio envolvendo cada fibra muscular (E). Hematoxilina-Eosina.

O arranjo ordenado das miofibrilas é responsável pelas estriações transversais, decorrentes da organização das proteínas contráteis em unidades idênticas, os sarcômeros, que constituem a unidade contrátil fundamental da fibra muscular. As faixas escuras são denominadas bandas A (anisotrópicas à luz polarizada) e as faixas claras, bandas I (isotrópicas à luz polarizada). No centro da banda A, pode-se observar uma fina faixa mais clara, a banda $\mathrm{H}$, formada somente pelos filamentos espessos. Na região central da banda $H$, observa-se a linha $\mathrm{M}$, formada por um arranjo hexagonal de proteínas que ligam filamentos espessos adjacentes. A Banda I é dividida por uma linha escura, o disco Z. A região da miofibrila, localizada entre dois discos $Z$, forma um sarcômero, com 2,5 $\mu \mathrm{m}$ de comprimento. A banda I é constituída somente pelos filamentos finos, que se estendem da linha $\mathrm{Z}$ até o início da Banda $\mathrm{H}$. Os principais componentes da banda A são filamentos espessos, localizados na região central do sarcômero (Figura 2).

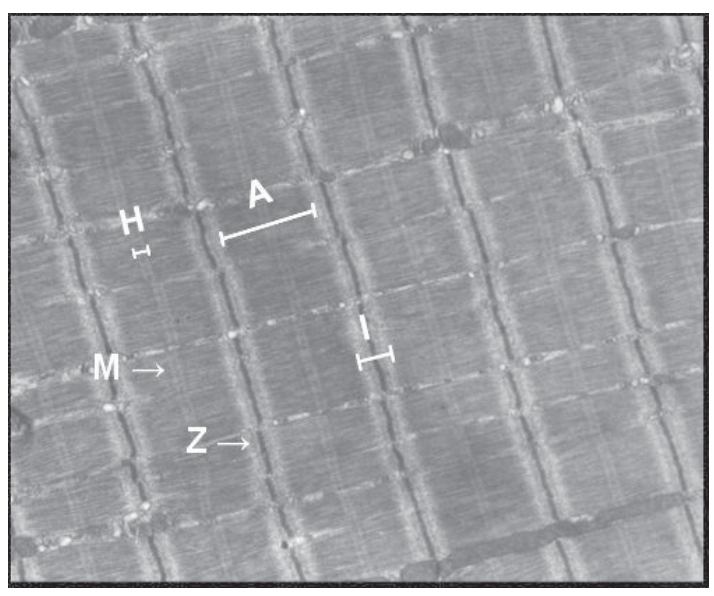

Figura 2 - Ultra-estrutura da fibra muscular estriada. Miofibrilas organizadas em sarcômeros com as bandas A, I, M e linha Z.

\section{Desenvolvimento embrionário do músculo esquelético}

A maioria dos músculos esqueléticos de aves e mamíferos, com exceção de alguns músculos craniofaciais e esofágicos, são formados a partir dos somitos, condensações transitórias do mesoderma paraxial originadas em cada lado do tudo neural do embrião (revisados em Summerbell \& Rigby, 2000; Pourquie, 2001; Pownall et al., 2002). Os somitos diferenciam-se ao longo do eixo dorso-ventral do embrião e originam o dermomiótomo, localizado dorsalmente, e o esclerótomo, localizado ventralmente (Figura 3). O dermomiótomo origina a derme e a musculatura esquelética dos membros e tronco, enquanto que o esclerótomo origina a cartilagem e os ossos das vértebras e costelas.

\footnotetext{
(C) 2007 Sociedade Brasileira de Zootecnia
} 
A porção epiaxial do dermomiótomo origina a musculatura profunda do dorso, a partir de células progenitoras da borda medial dorsal (BMD) que migram profundamente do dermomiótomo, saem do ciclo celular, se alongam e diferenciam-se em fibras musculares (Christ \& Ordahl, 1995; Amthor et al. 1999) (Figura 3). Um padrão similar de eventos induz a formação da borda lateral ventral (BLV) para estabelecer o dermomiótomo hipoaxial não migratório, o qual originará a musculatura lateral do tronco. Algumas células da BLV se separam do dermomiótomo e migram ventralmente para regiões de desenvolvimento dos músculos esqueléticos da parede ventral do corpo, da língua, dos membros e do diafragma.

A regulação do processo de formação dos músculos esqueléticos envolve a ativação, proliferação e diferenciação de várias linhagens de células miogênicas e depende da expressão e atividade de fatores transcricionais, conhecidos como fatores de regulação miogênica.
Fatores de regulação miogênica

Durante o desenvolvimento embrionário, o comprometimento das células somíticas do mesoderma com a linhagem miogênica depen-de inicialmente de sinais positivos [Wnts, Sonic hedgehog (Shh), Noggin] ou negativos (BMP4) oriundos de tecidos circundantes, tais como a notocorda e o tubo neural (revisado em Chargé \& Rudnicki, 2004). Esses sinais irão ativar os genes capazes de transformar células não musculares em células com um fenótipo muscular.

Os genes responsáveis por essa transfor-mação são membros da família dos fatores transcricionais basic helix-loop-helix (bHLH), da qual fazem parte a MyoD, Miogenina, Myf5 e o MRF4; coletivamente chamados de fatores de regulação miogênica (do inglês, myogenic regulatory factors ou MRFs). Os MRFs compartilham um domínio homólogo bHLH, que é necessário para a ligação com o DNA e para a dimerização com fatores transcricionais da família da proteína E. Os

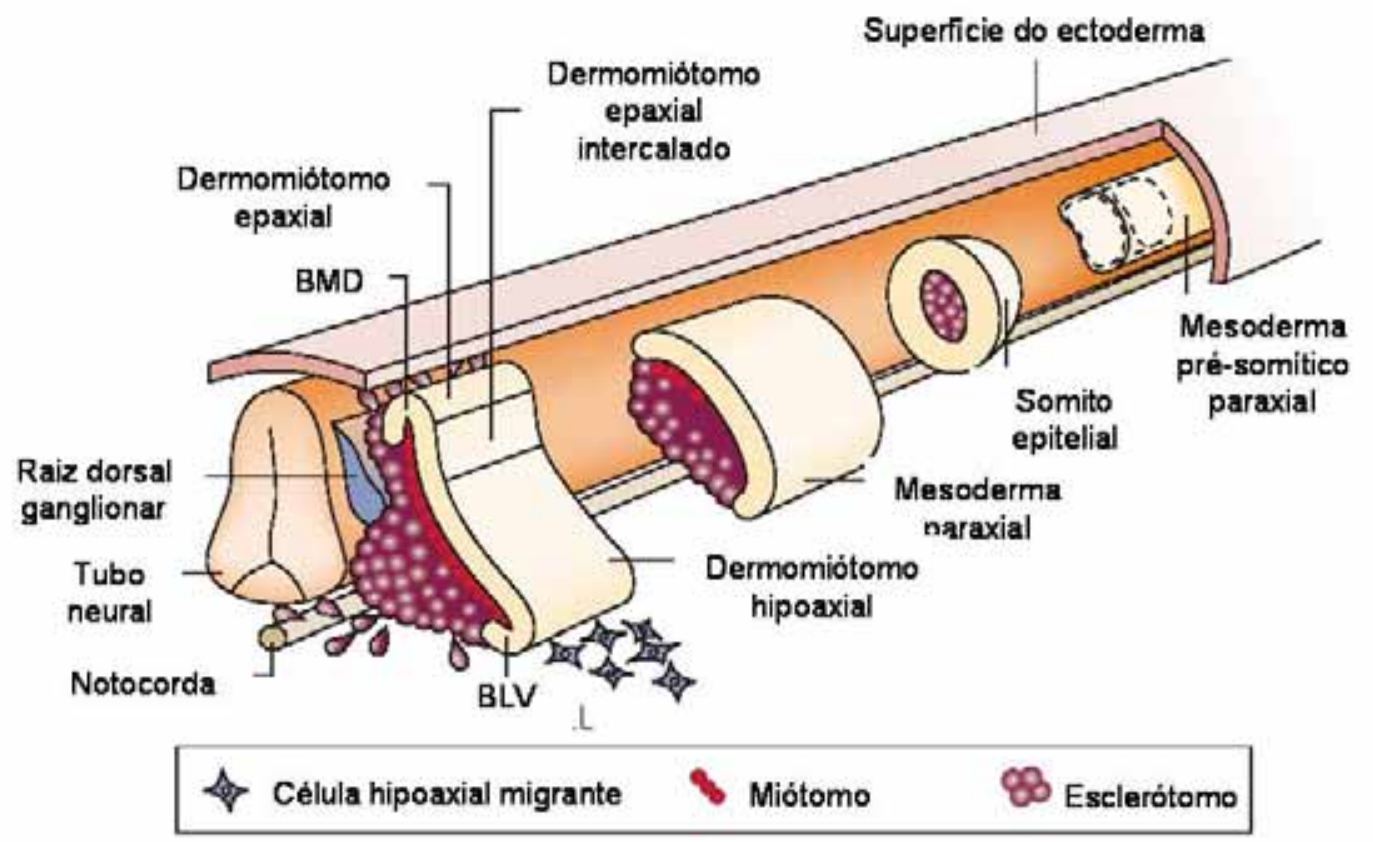

Figura 3 - Origem embrionária dos músculos do tronco e dos membros. O mesoderma paraxial présomítico está localizado em cada lado da notocorda. A segmentação do mesoderma paraxial em somitos ocorre ao longo do eixo dorso-ventral e em uma direção cefálica-caudal do embrião. Em resposta a sinais da notocorda e do tubo neural, os somitos se diferenciam e subdividem-se para originar o dermomiótomo e o esclerótomo. Células da borda medial dorsal (BMD) do dermomiótomo migram profundamente do dermomiótomo para formar o dermomiótomo epiaxial. Um evento semelhante ocorre na borda lateral ventral (BLV) do dermomiótomo, para a formação do dermomiótomo hipoaxial. Algumas células da BLV se separam do dermomiótomo e migram para regiões de desenvolvimento dos músculos da parede ventral do corpo, da língua, dos membros e do diafragma (células hipoaxiais migrantes) (adaptado de Parker et al., 2003). 
heterodímeros MRF-proteína $\mathrm{E}$ e os monômeros de MRFs ligam-se a seqüências de DNA (5'CANNTG-3'), conhecidas como Ebox, presentes na região promotora de vários genes músculo específicos, levando à expressão dos mesmos (Murre et al. 1989) (Figura 4).

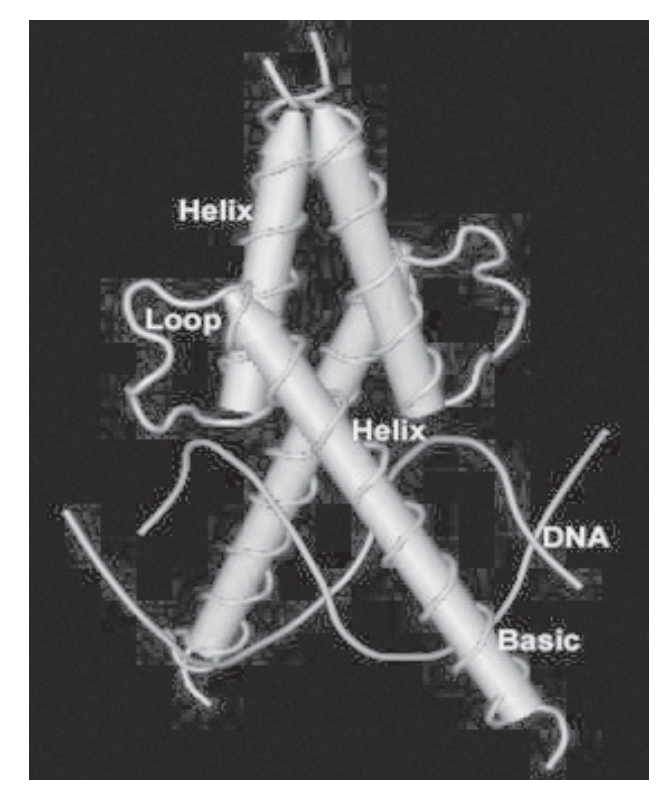

Figura 4 - Estrutura cristalográfica do complexo formado pelo dímero do fator transcricional da família basic Helix-Loop-Helix (bHLH) MyoD e o DNA (adaptado de Ma et al., 1994).

Assim como os MRFs, a família de fatores transcricionais MEF2 (do inglês, myocyte enhancer factor-2) também está envolvida na ativação de genes músculo - específicos (revisado em Naya \& Olson, 1999). Os MEF2 são expressos em muitos tecidos, mas é apenas durante o desenvolvimento dos músculos cardíaco, liso e estriado que esses fatores ativam a transcrição (Naya et al., 1999). Estudos demonstram uma ação interdependente entre a família MEF2 e os MRFs no controle da diferenciação do músculo esquelético (Naidu et al., 1995; Novitch et al., 1996; Novitch et al., 1999; Ridgeway et al., 2000).

$\mathrm{Na}$ diferenciação do músculo esquelético, o comprometimento das células somíticas do mesoderma com a linhagem miogênica é marcado pela expressão dos MRFs Myf5 e MyoD (Figura 5). Isso é demonstrado pela total ausência de tecido muscular em camundongos duplo Knockout MyoD:Myf5 e pela observação de que, nesses animais, as supostas células progenitoras muscu-

\footnotetext{
C 2007 Sociedade Brasileira de Zootecnia
}

lares permanecem multipotentes e contribuem para tecidos não musculares do tronco e dos membros desses camundongos (Rudnicki et al., 1993; Kablar et al., 1998). As células da linhagem miogênica em proliferação, positivas para Myf5 e/ou MyoD, são então denominadas de mioblastos (Megeney \& Rudnicki 1995).

Embora a MyoD e o Myf5 definam a identidade dos mioblastos, as células precursoras somíticas devem ser pré-comprometidas com a linhagem miogênica antes da expressão dos MRFs. No embrião, esse pré-comprometimento é realizado pelo fator transcricional Pax3, da família Pax (do inglês, paired-box), o qual é expresso em células do mesoderma pré-somítico e dos primeiros somitos epiteliais (Goulding et al., 1994; Williams \& Ordahl, 1994). Já no dermomiótomo, as células precursoras, que apresentam expressão de Pax3 induzida por sinais secretados pelo mesoderma da placa lateral e pelo ectoderma superficial, são mantidas como uma população não diferenciada e em proliferação; contribuindo assim para a expansão das células da linhagem miogênica (Amthor et al., 1999) (Figura 5).

Os mioblastos que saem do ciclo celular, que expressam Myf5 e MyoD, tornam-se miócitos diferenciados e iniciam a expressão dos MRFs miogenina e MRF4, os quais regulam a diferenciação dessas células em fibras musculares (Figura 5) (Megeney \& Rudnicki 1995). Embriões deficientes em miogenina morrem no período perinatal devido à deficiência na diferenciação dos miócitos, evidenciada pela quase total ausência de fibras musculares nesses mutantes (Hasty et al., 1993; Nabeshina et al., 1993). Similarmente, camundongos deficientes em MRF4 demonstram uma série de fenótipos consistentes com seu papel na diferenciação dos miócitos durante a miogênese (Patapoutian et al., 1995; Rawls et al., 1995; Zhang et al., 1995, Yoon et al., 1997).

Finalmente, no processo de miogênese, os miócitos mononucleados se fundem para formar os miotubos (Figura 5) e, no animal adulto, o músculo esquelético torna-se um tecido estável, caracterizado por fibras musculares multinucleadas (Decary et al., 1997; Schmalbruch \& Lewis, 2000). 


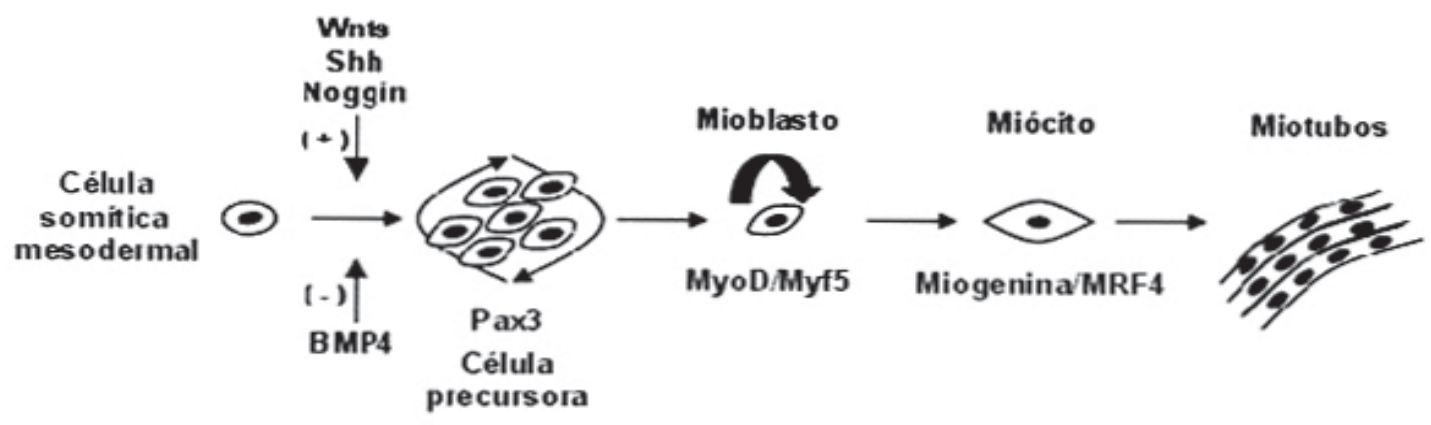

Figura 5 - Células somíticas mesodermais recebem sinais de tecidos circundantes os quais podem induzir [Wnts, Sonic hedgehog (Shh), Noggin] ou inibir (BMP4) a expressão de Myf5 e MyoD. A expressão de Pax3 nas células precursoras contribui para a expansão das células miogênicas. Após a indução de Myf5 e/ou MyoD, as células somíticas mesodermais são comprometidas com a linhagem miogênica (mioblastos). A expressão de miogenina e MRF4 induz a diferenciação dos mioblastos em miócitos. Posteriormente, os miócitos se fundem para originar os miotubos (adaptado de Chargé \& Rudnicki, 2004).

\section{Eventos celulares na formação dos músculos esqueléticos}

A formação dos músculos dos membros e do diafragma envolve pelo menos duas populações de mioblastos, os primários e os secundários (Hauschka, 1994) (Figura 6). A caracterização in vitro dessas duas populações de células demonstra uma distinção quanto à morfologia dos clones $\mathrm{e}$ às necessidades de meio de cultura (White et al., 1975; Rutz et al., 1982; Seed \& Hauschka, 1984). Além disso, há uma diferença na expressão das isoformas de cadeia pesada de miosina entre essas duas populações de células, sugerindo que os mioblastos primários são destinados a originar fibras lentas, enquanto que os secundários são destinados a originar fibras rápidas (para uma revisão, Stockdale, 1992). Entretanto, experimentos demonstram a importância de outros fatores, como a inervação, na determinação dos tipos de fibras musculares (Hughes \& Blau, 1992; Pin \& Merrifield, 1997).

A formação dos miotubos a partir dos mioblastos ocorre a partir de dois eventos distintos temporalmente (Figura 6). Inicialmente, ocorre a formação dos miotubos primários, os quais apresentam núcleos localizados na região central, e miofibrilas, na região periférica do sarcoplasma (Kelly \& Zacks, 1969; Ontell \& Kozeka, 1984). Esses miotubos fornecem um suporte (andaime) para a posterior formação dos miotubos secundários a partir da proliferação e fusão de mioblastos adjacentes aos miotubos primários (Ontell \&
Kozeka, 1984; Ross et al., 1987). Posteriormente, ocorre a separação dos miotubos primários e secundários e a diferenciação em fibras primárias e secundárias; os núcleos migram para a região periférica e as miofibrilas passam a ocupar todo o sarcoplasma (Ontell \& Kozeka, 1984; Ross et al., 1987).

\section{Células satélites musculares}

Durante o processo da miogênese, alguns mioblastos não se fundem e permanecem quiescentes entre a membrana plasmática da fibra muscular e a lâmina basal, sendo denominados de células satélites ou mioblastos adultos indiferenciados (Figura 6) (Mauro, 1961; Muir et al., 1965; para revisão ver Hawke and Garry, 2001; Chargé \& Rudnicki, 2004). As células satélites foram descritas pela primeira vez em músculos de rã, recebendo essa denominação pela sua posição em relação às fibras diferenciadas, sendo posteriormente identificadas em músculos de aves, répteis e mamíferos (Mauro, 1961; Gamble et al., 1978; Campion et al., 1981; Hartley et al., 1992; para revisão ver Bischoff, 1994). O número de células satélites no músculo é dependente da espécie, do tipo de fibra considerado e diminui na senilidade (Snow, 1977; Gibson \& Schultz, 1982; para revisão ver Schultz \& McCormick, 1994).

O crescimento do tecido muscular nos mamíferos, no período pós-natal, ocorre predominantemente por hipertrofia das fibras musculares, onde é observado um aumento do número de núcleos e

() 2007 Sociedade Brasileira de Zootecnia 
de miofibrilas nas fibras musculares pré-existentes a partir da proli-feração e diferenciação das células satélites (Moss \& Leblond, 1971). Quando estimulada, a célula satélite é ativada, prolifera e funde-se com a fibra muscular pré-existente. Os núcleos derivados das células satélites começam a sintetizar proteínas musculares específicas que aumentam o volume das fibras musculares através da formação de novos sarcômeros, em posição externa às miofibrilas existentes. $\mathrm{O}$ aumento do número de fibras musculares, processo conhecido como hiperplasia cessa em um curto período após o desenvolvimento embrionário (Goldspink et al., 1972). As células satélites apresentam também a capacidade de migração e essa característica é dependente da integridade da lâmina basal (Watt et al., 1987). Após a ruptura da lâmina basal, em decorrência de um miotrauma, as células satélites migram para a região da lesão para participar do processo de regeneração muscular, evento mediado pelas citocinas liberadas pelas células inflamatórias no local da lesão (Schultz et al., 1985; Schultz \& McCormick, 1994).

As células satélites expressam vários marcadores moleculares, como c-met (Tatsumi et al., 1998), VCAM1 (vascular cell adhesion molecule 1) (Jesse et al., 1998), Syndecan (Cornelison et al., 2001), M-caderin (Irintchev et al., 1994), CD34 (Beauchamp et al., 2000) e Pax7 (Seale et al., 2000). Quando ativadas, as células satélites expressam vários fatores transcricionais, entre eles, os fatores reguladores miogênicos MyoD, Myf5, miogenina e MRF4 (Holterman \& Rudnicki, 2005), que controlam a proliferação e a diferenciação celular.

\section{Tipos de fibras musculares estriadas}

Os primeiros estudos envolvendo o tecido muscular classificavam os músculos em vermelhos ou brancos (Ranvier, 1873). A cor vermelha está relacionada com a presença do pigmento

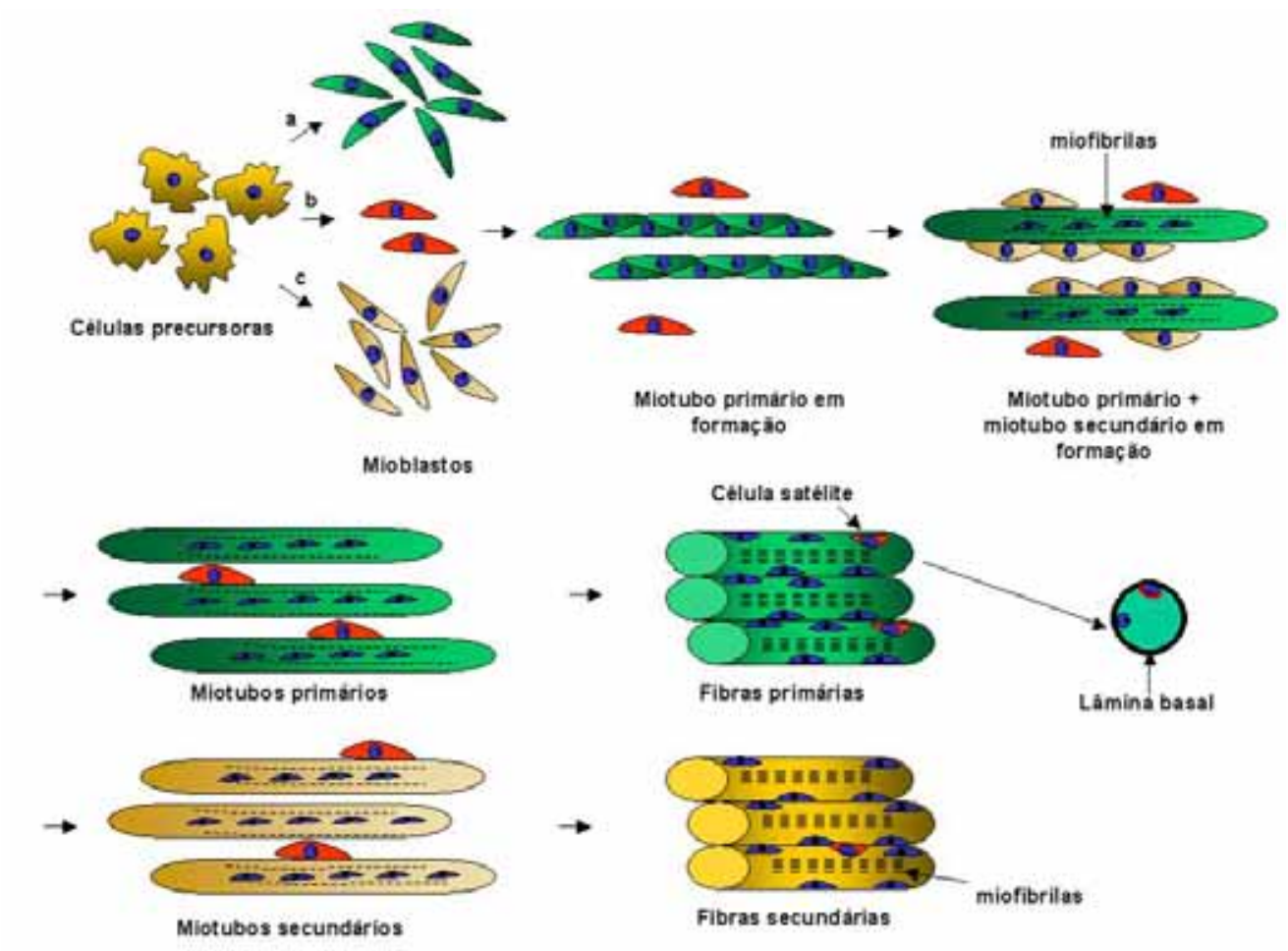

\footnotetext{
Figura 6 - Formação das fibras musculares estriadas. As células precursoras originam diferentes populações de mioblastos ( $\mathrm{a}, \mathrm{b}$ e c). Alguns mioblastos (a) se alinham e fundem-se formando os miotubos primários, que apresentam núcleos na região central e, iniciam a síntese de miofibrilas que ocupam a região periférica no sarcoplasma do miotubo. Os miotubos primários fornecem o suporte para a subseqüente formação dos miotubos secundários, a partir de outra população de mioblastos (c). Posteriormente ocorre a separação dos miotubos primários e secundários e a diferenciação em fibras primárias e secundárias. Os núcleos das fibras migram para a região periférica da fibra e as miofibrilas passam a ocupar todo o sarcoplasma. Alguns mioblastos (b), denominados de células satélites, não se fundem e permanecem quiescentes entre a membrana plasmática da fibra e a lâmina basal (Dal Pai-Silva et al. 2005).
}

(C) 2007 Sociedade Brasileira de Zootecnia 
mioglobina e com o grau de vascularização do músculo. Com a utilização de técnicas histoquímicas, observou-se que a maioria dos músculos estriados dos mamíferos é constituída por uma população heterogênea de fibras, que apresentam características morfológicas, bioquímicas e fisiológicas distintas (Dubowitz \& Pearse, 1960). Inicial-mente, as fibras musculares foram classificadas em vermelhas, intermediárias e brancas (Ogata, 1958). Posteriormente, três tipos principais de fibras musculares foram descritas, sendo denominadas de fibras dos tipos I, IIA e IIB, de acordo com o padrão de reação para a atividade da ATPase da porção globular da cadeia pesada da miosina (ATPase miofibrilar ou m-ATPase) (Brooke \& Kaiser, 1970).

A molécula de miosina é um hexâmero formado por duas cadeias pesadas de miosina (do inglês, myosin heavy chain ou MHC), enroladas em $\alpha$ hélice, e quatro cadeias leves de miosina (do inglês, myosin light chain ou MLC) (Lowey et al. 1969; Weeds \& Lowey, 1971; Elliot \& Offer, 1978; Warrick \& Spudich, 1987). Cada cadeia pesada pode ser separada em duas porções: meromiosina leve, em forma de bastão, e meromiosina pesada, conhecida como porção globosa da miosina, a qual apresenta o sítio de ligação com a actina e a região capaz de ligar-se à molécula de ATP e hidrolisá-la (atividade ATPásica) (Huxley 1969; Lowey et al., 1969) (Figura 7).

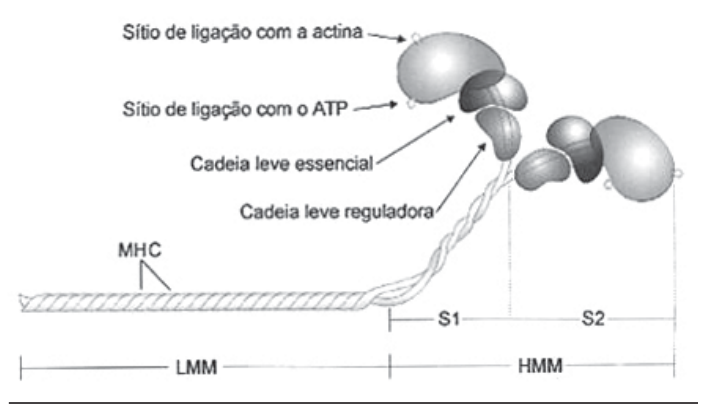

Figura 7 - Esquema da molécula de miosina da classe II. Cada molécula de miosina é composta por duas cadeias pesadas de miosina (MHC) e quatro cadeias leves de miosina (MLC). As MHC podem ser clivadas e gerar as meromiosina leves (LMM) e meromiosina pesadas (HMM). As HMM são compostas pela porção globosa S1 e pela porção a hélice em forma de bastão, S2. As MLC estão dispostas na proporção de duas cadeias (uma essencial e uma reguladora) para cada subfragmento S1 (Dal PaiSilva et al., 2005).
Ashmore \& Doerr (1971), utilizando a combinação das reações histoquímicas para detecção da atividade das enzimas m-ATPase e succinato desidrogenase (SDH), classifica-ram as fibras musculares como $\alpha$ Red, $\alpha$ Red e $\alpha$ White. Posteriormente, Peter et al. (1972), classificaram as fibras musculares em SO (slow oxidative), FOG (Fast oxidative glycolytic) e FG (Fast glycolytic), baseando-se na combinação das reações histoquímicas e na detecção da atividade das enzimas m-ATPase e NADH tetrazólio redutase (NADH-TR).

Estudos mais recentes, envolvendo a microdissecção de fibras e, associando a reação histoquímica m-ATPase com a técnica da eletroforese, possibilitaram a separação de quatro isoformas de cadeia pesada de miosina (MHC) presentes nas fibras musculares: fibras do tipo I, com MHCI, fibras do tipo IIA, com MHC IIa, fibras do tipo IIB, com MHC IIb e fibras do tipo IID com MHC IId (Termin et al. 1989). A MHCIId está presente nos músculos de pequenos mamíferos e possui uma velocidade de contração intermediaria entre as MHCIIa e MHCIIb (Hilber et al., 1999). As fibras IID apresentam características histoquímicas e bioquímicas similares às fibras $2 \mathrm{X}$ descritas em ratos (Larsson et al., 1991), camundongos e coelhos (Hämäläinen \& Pette, 1993), sendo também denominadas de fibras IID/IIX (para uma revisão ver Scott et al., 2001). Baseado em vários tipos de evidências e na análise de seqüências de DNA, a MHC riginalmente identificada em humanos como MHCIIb é na verdade homóloga à MHCIId/IIx presente nas fibras IID/IIX de pequenos mamíferos (Pette \& Staron, 1997). Portanto, os humanos expressam as seguintes isoformas de MHC (da mais lenta para a mais rápida): $\mathrm{MHCI}$, MHCIIa e MHCIIx/d (Staron, 1997); e não expressam a mais rápida isoforma de todas as MHC, a MHCIIb (Hilber et al., 1999).

As fibras do tipo I, IIA, IID/X e IIB são classificadas como fibras puras (Pette \& Staron, 1997; Staron et al. 1999). Porém, além das fibras puras, que expressam apenas um tipo de RNA mensageiro para a $\mathrm{MHC}$, há fibras que coexpressam diferentes genes para a MHC (Biral et al., 1988; Aigner et al., 1993; Schiaffino \& Reggiani, 1994; Caiozzo et al., 2003). Essas fibras são classificadas de acordo com o tipo de MHC predominante: $(\mathrm{IC}=\mathrm{MHCI}>\mathrm{MHCIIa}, \mathrm{IIC}=$

(C) 2007 Sociedade Brasileira de Zootecnia 
MHCIIa $>$ MHCI, IIAD $=$ MHCIIa $>$ MHCIId, IIBD $=$ MHCIIb $>$ MHCIId), sendo denominadas de fibras híbridas ou polimórficas (Staron \& Pette, 1993; Di Maso et al., 2000).

A velocidade de contração de uma fibra muscular está diretamente relacionada com o tipo de MHC (revisado em Talmadge et al., 1993). A MHC capaz de rápida hidrólise do ATP é característica das fibras do tipo II, que são fibras de contração rápida. Já a MHC de baixa atividade ATPásica é encontrada nas fibras do tipo I, de contração lenta (Kelly \& Rubinstein, 1994).

A identificação das características contráteis das fibras musculares é importante, pois como os músculos são compostos por vários tipos de fibras musculares, suas propriedades refletem a soma das características das fibras que o constituem. Isso é possível pois a estrutura da matriz extracelular do músculo esquelético permite a combinação das forças geradas pela contração de várias fibras musculares, a qual é transformada em movimento via junções miotendinosas, onde as fibras musculares se aderem ao esqueleto pelos tendões (revisado em Kjaer 2004).

\section{Matriz extracelular do músculo esquelético}

As fibras musculares estão envoltas por uma matriz extracelular rica em carboidratos e proteínas, que constituem o tecido conjuntivo do músculo; organizado em três bainhas: epimísio, que circunda todo o músculo; perimísio, que divide o músculo em fascículos e endomísio, que circunda cada fibra muscular (para uma revisão ver Sanes, 2003 e Kjaer, 2004) (Figura 8).

Estudos de microscopia óptica revelaram inicialmente que cada fibra muscular está envolvida por um delicado tubo, denominado sarcolema, formado por 3 componentes: fibrilas reticulares, que seguem um curso em espiral ao redor da fibra (Borg \& Caulfield, 1980), membrana basal (Zacks et al., 1973; Borg \& Caulfield, 1980) e membrana plasmá-tica da fibra muscular. A membrana basal é formada por duas discretas camadas: a lâmina reticular e a lâmina basal (Mauro \& Adams, 1961). Posteriormente, estudos de microscopia eletrônica demonstraram que a lâmina basal é ainda subdividida em lâmina densa (10 a 15 nm de espessura) e lâmina rara (2 a 5 nm de espessura), adjacente à

\footnotetext{
() 2007 Sociedade Brasileira de Zootecnia
}

membrana plasmática (Inoue, 1989). Os principais componentes da membrana basal são: laminina, fibronectina, entactina, heparam sulfato e os colágenos dos tipos I, III, IV, V e VI (Duance et al., 1977; Duance et al., 1980; Walsh et al., 1981; Foidart et al., 1981; Sanes, 1982; Stephens et al., 1982; Bayne et al., 1984; Linsenmayer et al., 1986; Eldridge et al., 1986; Lehto et al., 1988). Na superfície externa da membrana plasmática, observa-se uma camada de glicoproteínas, o glicocálix, que se continua com a lâmina basal.

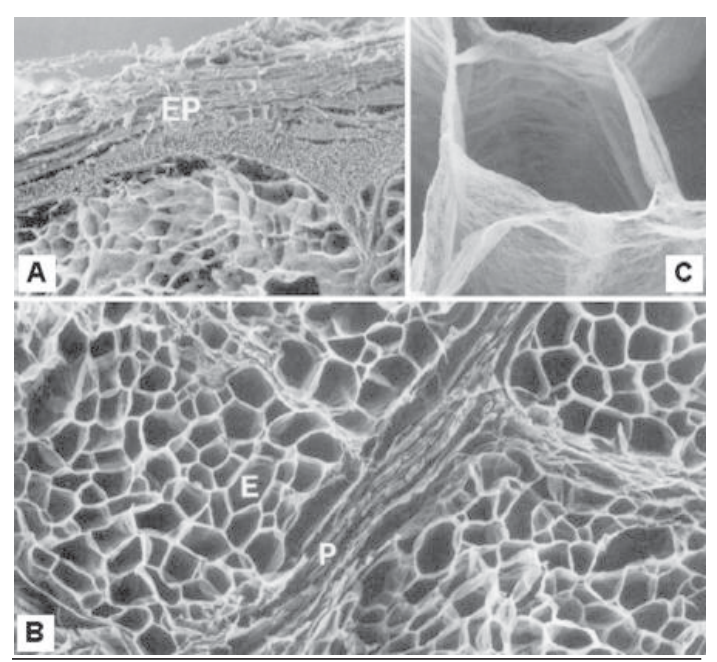

Figura 8 - Estrutura da matriz extracelular do músculo esquelético. Músculo semitendinoso bovino após remoção das proteínas das fibras musculares (microscopia eletrônica de varredura). A: Epimísio (EP), B: Perimísio (P) e Endomísio (E). C: Detalhe do endomísio circundando uma fibra muscular esquelética. (adaptado de Kjaer, 2004)

Poucas moléculas têm sido localizadas no epimísio e no perimísio (Bailey \& Sims, 1977; Duance et al., 1977; Duance et al., 1980; Foidart et al., 1981; Sanes, 1982; Stephens et al., 1982; Linsenmayer et al., 1986; Lehto et al.,1988; Light \& Champion, 1984). A fibro-nectina está presente em ambas camadas, bem como os colágenos dos tipos V e VI. O colágeno do tipo I está concentrado no epimísio e o colágeno do tipo III no perimísio, ambos presentes em concentrações maiores no epi - e perimísio que no endomísio. Laminina e colágeno IV estão presentes no local de contato da lâmina basal com o perimísio, mas ausentes no perimísio e endomísio propriamente ditos. 


\section{Literatura citada}

AIGNER, S.; GOHLSCH, B.; HAMALAINEN, N.et al. Fast myosin heavy chain diversity in skeletal muscles of the rabbit: heavy chain IId, not IIb predominates. Eur J Biochem, v.211, n.1-2, p.367-372, 1993 .

AMTHOR, H.; CHRIST, B.; PATEL, K. A molecular mechanism enabling continuous embryonic muscle growth - a balance between proliferation and differentiation. Development, v.126, n.5, p.1041-1053, 1999.

ASHMORE, C.R.; DOERR, L. Comparative aspects of muscle fiber types in different species. Exp Neurol, v.31, n.3, p.408418, 1971.

BAILEY, A.J.; SIMS, T.J. Meat tenderness: distribution of molecular species of collagen in bovine muscle. J Sci Food Agric, v.28, n.6, p.565-570, 1977.

BAYNE, E.K.; ANDERSON, M.J.; FAMBROUGH, D.M. Extracellular matrix organization in developing muscle: correlation with acetylcholine receptor aggregates. J Cell Biol, v.99, n.4, Pt 1, p.1486-1501, 1984.

BEAUCHAMP, J.R.; HESLOP, L.; YU, D.S. et al. Expression of CD34 and Myf5 defines the majority of quiescent adult skeletal muscle satellite cells. J. Cell Biol, v. 151, n.6, p. 1221-1234, 2000.

BIRAL, D.; BETTO, R.; DANIELI-BETTO, D. et al. Myosin heavy chain composition of single fibres from normal human muscle. Biochem J, v.250, n.1, p.307-308, 1988.

BISCHOFF, R. The satellite cell and muscle regeneration.In: ENGEL, A.G.; FRANZINI-ARMSTRONG, C. (Eds.) Myology. New York: McGraw-Hill, 1994. p.97-118.

BORG, T.K.; CAULFIELD, J.B. Morphology of connective tissue in skeletal muscle. Tissue Cell, v.12, n.1, p.197-207, 1980.

BROOKE, M.H.; KAISER, K.K. Three "myosin adenosine triphosphatase" systems: the nature of their $\mathrm{pH}$ lability and sulfhydryl dependence. J Histochem Cytochem, v.18, n.9, p.670-672, 1970.

CAIOZZO, V.J.; BAKER, M.J.; HUANG, K. et al. Single-fiber myosin heavy chain polymorphism: how many patterns and what proportions? Am J Physiol Regul Integr Comp Physiol, v.285, n.3, p.R570-580, 2003.

CAMPION, D.R.; RICHARDSON, R.L.; REAGAN, J.O. et al. Changes in the satellite cell population during postnatal growth of pig skeletal muscle. J Anim Sci., v.52, p.1014$1018,1981$.

CHARGÉ, S.B.; RUDNICKI, M.A. Cellular and molecular regulation of muscle regeneration. Physiol Rev., v.84, n.1, p.209-238, 2004.

CHRIST, B.; ORDAHL, C.P. Early stages of chick somite development. Anat Embryol (Berl), v.191, n.5, p.381-396, 1995.

CORNELISON, D.D.; FILLA, M.S.; STANLEY, H.M. et al. Syndecan-3 and syndecan-4 specifically mark skeletal muscle satellite cells and are implicated in satellite cell maintenance and muscle regeneration. Dev. Biol., v. 239, n.1, p. 79-94, 2001.

DAL PAI-SILVA, M.; DAL PAI, V.; CARVALHO, R.F. Célula Muscular Estriada Esquelética. In: CARVALHO, H.F.; COLlares-BUZATO, C.B. (Eds.) Células: uma abordagem multidisciplinar. Editora Manole: São Paulo, 2005. p.83-94.

DECARY, S.; MOULY, V.; HAMIDA, C.B. et al. Replicative potential and telomere length in human skeletal muscle: implications for satellite cell-mediated gene therapy. Hum Gene Ther., v.8, n.12, p.1429-1438, 1997.

DI MASO, N.A.; CAIOZZO, V.J.; BALDWIN, K.M. Singlefiber myosin heavy chain polymorphism during postnatal development: modulation by hypothyroidism. Am J Physiol Regul Integr Comp Physiol., v.278, n.4, p.R1099-1106, 2000 .
DUANCE, V.C.; BLACK, C.M.; DUBOWITZ, V. et al. Polymyositis - an immunofluorescence study on the distribution of collagen types. Muscle Nerve, v.3, n.6, p.487490, 1980.

DUANCE, V.C.; RESTALL, D.J.; BEARD, H. et al. The location of three collagen types in skeletal muscle. FEBS Lett, v.79, n.2, p.248-252, 1977.

DUBOWITZ, V.; PEARSE, A.G. A comparative histochemical study of oxidative enzyme and phosphorylase activity in skeletal muscle. Z Zellforch Microsk Anat Histochem, v.2, p.105-117, 1960 .

ELDRIDGE, C.F.; SANES, J.R.; CHIU, A.Y. et al. Basal laminaassociated heparan sulphate proteoglycan in the rat PNS: characterization and localization using monoclonal antibodies. J Neurocytol, v.15, n.1, p.37-51, 1986.

ELLIOTT, A.; OFFER, G. Shape and flexibility of the myosin molecule. J Mol Biol, v.123, n.4, p.505-519, 1978.

FOIDART, M.; FOIDART, J.M.; ENGEL, W.K. Collagen localization in normal and fibrotic human skeletal muscle. Arch Neurol, v.38, n.3, p.152-157, 1981.

GAMBLE, H.J.; FENTON, J.; ALLSOPP, G. Electron microscope observations on human fetal striated muscle. J Anat, v.126, n.3, p.567-589, 1978.

GIBSON, M.C.; SCHULTZ, E. The distribution of satellite cells and their relationship to specific fiber types in soleus and extensor digitorum longus muscles. Anat Rec, v.202, n.3, p.329-37, 1982.

GOLDsPinK, G.; WILKES, D.; STEVEN, E. Myosin expression during ontogeny post-hatching growth and adaptation. In: JOHNSTON, I.A. (Ed.) Muscle development and growth. Academic Press: London, 1972. p.318.

GOULDING, M.; LUMSDEN, A.; PAQUETTE, A.J. Regulation of Pax-3 expression in the dermomyotome and its role in muscle development. Development, v.120, n.4, p.957-971, 1994.

HÄMÄLÄINEN, N.; PETTE, D. The histochemical profiles of fast fiber types IIB, IID, and IIA in skeletal muscles of mouse, rat, and rabbit. J Histochem Cytochem, v.41, n.5, p.733743, 1993.

HARTLEY, R.S.; BANDMAN, E.; YABLONKA-REUVENI, Z. Skeletal muscle satellite cells appear during late chicken embryogenesis. Dev Biol, v.153, n.2, p.206-216, 1992.

HASTY, P.; BRADLEY, A.; MORRIS, J.H. et al. Muscle deficiency and neonatal death in mice with a targeted mutation in the myogenin gene. Nature, v.364, n.6437, p.501-506, 1993.

HAUSCHKA, S.D. The embryonic origin of muscle. In: ENGEL, A.G.; FRANZINI-ARMSTRONG, C. (Eds.). Myology. 2. ed. McGraw-Hill: London, 1994. p.3-73.

HAWKE, T.J.; GARRY, D.J. Myogenic satellite cells physiology to molecular biology. J Appl Physiol, v.91, p.534-551, 2001.

HILBER, K.; GALLER, S.; GOHLSCH, B. et al. Kinetic properties of myosin heavy chain isoforms in single fibers from human skeletal muscle. FEBS Lett, v.455, n.3, p.267$270,1999$.

HOLTERMAN, C.E. \& RUDNICKI, M.A. Molecular regulation of satellite cell function. Seminars in Cell \& Dev. Biol., v. 16, p.575-584, 2005.

HUGHES, S.M.; BLAU, H.M. Muscle fiber pattern is independent of cell lineage in postnatal rodent development. Cell, v.68, n.4, p.659-671, 1992.

HUXLEY, H.E. The mechanism of muscular contraction. Science, v.164, n.886, p.1356-65, 1969.

INOUE, S. Ultrastructure of basement membranes. Int Rev Cytol, v.117, p.57-98, 1989.

KABLAR, B.; ASAKURA, A.; KRASTEL, K. et al. MyoD and Myf-5 define the specification of musculature of distinct embryonic origin. Biochem Cell Biol, v.76, n.6, p.1079-1091, 1998.

IRINTCHEV, A.; ZESCHNIGK, M.; STARZINSKI- POWITZ, 
A. et al. Expression pattern of M-cadherin in normal, denervated, and regenerating mouse muscles. Dev. Dyn, v. 199, n. 4. p. 326-337, 1994.

JESSE, T.L.; LACHANCE, R.; IADEMARCO, M.F. et al. Interferon regulatory factor- 2 is a transcriptional activator in muscle where it regulates expression of vascular cell adhesion molecule-1. J. Cell Biol, v. 140, n. 5, p. 1265-1276, 1998.

KELLY, A.M.; RUBINSTEIN, N.A. The diversity of muscle fiber types and its origin during development. In: ENGEL, A.G.; FRANZINI-ARMSTRONG, C. (Eds) Myology, 2ed. McGraw-Hill: London, 1994. p.119-133.

KELLY, A.M.; ZACKS, S.I. The histogenesis of rat intercostal muscle. J Cell Biol, v. 42, n.1, p.135-53, 1969.

KJAER, M. Role of extracellular matrix in adaptation of tendon and skeletal muscle to mechanical loading. Physiol Rev, v.84, n.2, p.649-698, 2004.

LARSSON, L.; EDSTROM, L.; LINDEGREN, B. et al. MHC composition and enzyme-histochemical and physiological properties of a novel fast-twitch motor unit type. Am J Physiol, v.261, n.1 Pt 1, p.C93-101, 1991.

LEHTO, M.; KVIST, M.; VIENO, T. Macromolecular composition of the sarcolemma and endomysium in the rat. Acta Anat (Basel), v.133, n.4, p.297-302, 1988.

LIGHT, N.; CHAMPION, A.E. Characterization of muscle epimysium, perimysium and endomysium collagens. Biochem J, v.219, n.3, p.1017-1026, 1984.

LINSENMAYER, T.F.; MENTZER, A.; IRWIN, M.H. et al. Avian type VI collagen. Monoclonal antibody production and immunohistochemical identification as a major connective tissue component of cornea and skeletal muscle. Exp Cell Res, v.165, n.2, p.518-529, 1986.

LOWEY, S.; SLAYTER, H.S.; WEEDS, A.G. et al. Substructure of the myosin molecule. I. Subfragments of myosin by enzymic degradation. J Mol Biol, v.42, n.1, p.1-29, 1969.

MA, P.C.; ROULD, M.A.; WEINTRAUB, H.; PABO, C.O. Crystal structure of MyoD bHLH domain-DNA complex: perspectives on DNA recognition and implications for transcriptional activation. Cell, v.77, n.3, p.451-459, 1994.

MAURO, A. Satellite cell of skeletal muscle fibers. J Biophys Biochem Cytol, v.9, p. 493-495, 1961.

MAURO, A.; ADAMS, W.R. The structure of the sarcolemma of the frog skeletal muscle fiber. J Biophys Biochem Cytol, v.10, n.4, Suppl, p.177-185, 1961.

MEGENEY, L.A.; RUDNICKI, M.A. Determination versus differentiation and the MyoD family of transcription factors. Biochem Cell Biol, v.73, n.9-10, p.723-732, 1995.

MOSS, F.P.; LEBLOND, C.P. Satellite cells as the source of nuclei in muscles of growing rats. Anat Rec, v.170, p.42136, 1971.

MUIR, A.R.; KANJI, A.H.; ALLBROOK, D. The structure of the satellite cells in skeletal muscle. J Anat, v.99, p.435-444, 1965.

MURRE, C.; McCAW, P.S.; VAESSIN, H. et al. Interactions between heterologous helix-loop-helix proteins generate complexes that bind specifically to a common DNA sequence. Cell, v.58, n.3, p.537-544, 1989.

NABESHIMA, Y.; HANAOKA, K.; HAYASAKA, M. et al. Myogenin gene disruption results in perinatal lethality because of severe muscle defect. Nature, v.364, n.6437, p.532-535, 1993.

NAIDU, P.S.; LUDOLPH, D.C.; TO, R.Q. et al. Myogenin and MEF2 function synergistically to activate the MRF4 promoter during myogenesis. Mol Cell Biol, v.15, n.5, p.2707-2718, 1995.

NAYA, F.J.; OLSON, E. MEF2: a transcriptional target for signaling pathways controlling skeletal muscle growth and differentiation. Curr Opin Cell Biol, v.11, n.6, p.683-688, 1999.

NAYA, F.J.; WU, C.; RICHARDSON, J.A. et al. Transcriptional activity of MEF2 during mouse embryogenesis monitored with a MEF2-dependent transgene. Development, v.126, n.10, p.2045-2052, 1999.

NOVITCH, B.G, MULLIGAN, G.J.; JACKS, T. et al. Skeletal muscle cells lacking the retinoblastoma protein display defects in muscle gene expression and accumulate in $\mathrm{S}$ and G2 phases of the cell cycle. J Cell Biol, v.135, n.2, p.441456, 1996.

NOVITCH, B.G.; SPICER, D.B.; KIM, P.S. et al. pRb is required for MEF2-dependent gene expression as well as cell-cycle arrest during skeletal muscle differentiation. Curr Biol, v.9, n.9, p.449-459, 1999.

OGATA, T. A histochemical studies on red and white muscle fibres. Part III. Activity of the diphosphopyridine nucleotide diaphorase and triphosphopyridine nucleotide diaphorase in muscle fibres. Acta Med. Okayama, v.12, p. 233-240, 1958.

ONTELL, M.; KOZEKA, K. The organogenesis of murine striated muscle: a cytoarchitectural study. Am J Anat, v.171, n.2, p.133-148, 1984.

PARKER, M.H.; SEALE, P.; RUDNICKI, M. A. Looking back to the embryo: defining transcriptional networks in adult myogenesis. Nat Rev Genet, v.4, n.7, p.497-507, 2003.

PATAPOUTIAN, A.; YOON, J.K.; MINER, J.H. et al. Disruption of the mouse MRF4 gene identifies multiple waves of myogenesis in the myotome. Development, v.121, n.10, p.3347-3358, 1995.

PETER, J.B.; BARNARD, R.J.; EDGERTON, V.R. et al. Metabolic profiles of three fiber types of skeletal muscle in guinea pigs and rabbits. Biochemistry, v.11, n.14, p.26272633, 1972.

PETTE, D.; STARON, R.S. Mammalian skeletal muscle fiber type transitions. Int Rev Cytol, v.170, p.143-223, 1997.

PIN, C.L.; MERRIFIELD, P.A. Developmental potential of rat L6 myoblasts in vivo following injection into regenerating muscles. Dev Biol, v.188, n.1, p.147-166, 1997.

POURQUIE, O. Vertebrate somitogenesis. Annu Rev Cell Dev Biol, v.17, p.311-350, 2001.

POWNALL, M.E.; GUSTAFSSON, M.K.; EMERSON, C.P. Myogenic regulatory factors and the specification of muscle progenitors in vertebrate embryos. Annu Rev Cell Dev Biol, v.8, p.747-783, 2002.

RANVIER, L. Properties et structures differents des muscles rouges et des muscles blancs chez les lapins et chez les raies. CR Hebd Seances Acad Sci, v.7, p.2062-2072, 1873.

RAWLS, A.; MORRIS, J.H.; RUDNICKI, M. et al. Myogenin's functions do not overlap with those of MyoD or Myf-5 during mouse embryogenesis. Dev Biol, v.172, n.1, p.37-50, 1995.

RIDGEWAY, A.G.; WILTON, S.; SKERJANC, I.S. Myocyte enhancer factor $2 \mathrm{C}$ and myogenin up-regulate each other's expression and induce the development of skeletal muscle in P19 cells. J Biol Chem, v.275, n.1, p.41-46, 2000.

ROSS, J.J.; DUXSON, M.J.; HARRIS, A.J. Formation of primary and secondary myotubes in rat lumbrical muscles. Development, v.100, n.3, p.383-394, 1987.

RUDNICKI, M.A.; SCHNEGELSBERG, P.N.; STEAD, R.H. et al. MyoD or Myf-5 is required for the formation of skeletal muscle. Cell, v.75, n.7, p.1351-1359, 1993.

RUTZ, R.; HANEY, C.; HAUSCHKA, S. Spatial analysis of limb bud myogenesis: a proximodistal gradient of muscle colony-forming cells in chick embryo leg buds. Dev Biol, v.90, n.2, p.399-411, 1982.

SANES, J.R. Laminin, fibronectin, and collagen in synaptic and extrasynaptic portions of muscle fiber basement membrane. J Cell Biol, v.93, n.2, p.442-451, 1982.

SANES, J.R. The basement membrane/basal lamina of skeletal muscle. J Biol Chem, v.278, n.15, p.12601-12604, 2003.

SCHIAFFINO, S.; REGGIANI, C. Myosin isoforms in mammalian skeletal muscle.

J Appl Physiol, v.77, n.2, p.493-501, 1994.

SCHMALBRUCH, H.; LEWIS, D.M. Dynamics of nuclei of muscle fibers and connective tissue cells in normal and

두 2007 Sociedade Brasileira de Zootecnia 
denervated rat muscles. Muscle Nerve, v.23, n.4, p.617-626, 2000.

SCHULTZ, E.; JARYSZAK, D.L.; VALLIERE, C.R. Response of satellite cells to focal skeletal muscle injury. Muscle Nerve, v.8, p.217-222, 1985.

SCHULTZ, E.; McCORMICK, K.M. Skeletal muscle satellite cells. Rev Physiol Biochem Pharmacol, v.123, p.213-257, 1994.

SCOTT, W.; STEVENS, J.; BINDER-MACLEOD, S.A. Human skeletal muscle fiber type classifications. Phys Ther, v.81, n.11, p.1810-1816, 2001.

SEALE, P.; SABOURIN, L.A.; GIRGIS-GABARDO, A. et al. $\operatorname{Pax} 7$ is required for the specification of myogenic satellite cells. Cell, v.102, n. 6, p. 777-786, 2000.

SEED, J.; HAUSCHKA, S.D. Temporal separation of the migration of distinct myogenic precursor populations into the developing chick wing bud. Dev Biol, v.106, n.2, p.389393, 1984.

SNOW, M.H. The effects of aging on satellite cells in skeletal muscles of mice and rats. Cell Tissue Res, v.185, n.3, p.399408, 1977.

STARON, R.S. Human skeletal muscle fiber types: delineation, development, and distribution. Can J Appl Physiol, v.22, n.4, p.307-327, 1997.

STARON, R.S.; KRAEMER, W.J.; HIKIDA, R.S. et al. Fiber type composition of four hindlimb muscles of adult Fisher 344 rats. Histochem Cell Biol, v.111, n.2, p.117-123, 1999.

STARON, R.S.; PETTE, D. The continuum of pure and hybrid myosin heavy chain-based fibre types in rat skeletal muscle. Histochemistry, v.100, n.2, p.149-153, 1993.

STEPHENS, H.R.; DUANCE, V.C.; DUNN, M.J. et al. Collagen types in neuromuscular diseases. J Neurol Sci, v.53, n. 1, p.4562, 1982.

STOCKDALE, F.E. Myogenic cell lineages. Dev Biol, v.154, n.2, p.284-298, 1992.

SUMMERBELL, D.; RIGBY, P.W. Transcriptional regulation during somitogenesis. Curr Top Dev Biol, v.48, p.301-318, 2000 .

TALMADGE, R.J.; ROY, R.R.; EDGERTON, V.R. Muscle fiber types and function. Curr Opin Rheumatol, v.5, n.6, p.695705, 1993.

TATSUMI, R.; ANDERSON, J.E.; NEVORET, C.J. et al. HGF/ $\mathrm{SF}$ is present in normal adult skeletal muscle and is capable of activating satellite cells. Dev. Biol, v. 194, n.1, p. 114128, 1998.

TERMIN, A.; STARON, R.S.; PETTE, D. Myosin heavy chain isoforms in histochemically defined fiber types of rat muscle. Histochemistry, v.92, n.6, p.453-457, 1989.

WALSH, F.S.; MOORE, S.E.; DHUT, S. Monoclonal antibody to human fibronectin: production and characterization using human muscle cultures. Dev Biol, v.84, n.1., p.121-132, 1981.

WARRICK, H.M.; SPUDICH, J.A. Myosin structure and function in cell motility. Annu Rev Cell Biol, v.3, p.379421, 1987.

WATT, D.J.; MORGAN, J.E.; CLIFFORD, M.A. The movement of muscle precursor cells between adjacent regenerating muscles in the mouse. Anat Embryol, v.175, p.527-536, 1987.

WEEDS, A.G.; LOWEY, S. Substructure of the myosin molecule. II. The light chains of myosin. J Mol Biol, v.61, n.3, p.701-725, 1971.

WHITE, N.K.; BONNER, P.H.; NELSON, D.R. et al. Clonal analysis of vertebrate myogenesis. IV. Medium-dependent classification of colony-forming cells. Dev Biol, v.44, n.2, p.346-361, 1975.

WILLIAMS, B.A.; ORDAHL, C.P. Pax-3 expression in segmental mesoderm marks early stages in myogenic cell specification. Development, v.120, n.4, p.785-796, 1994.

YOON, J.K.; OLSON, E.N.; ARNOLD, H.H. et al. Different MRF4 knockout alleles differentially disrupt Myf-5 expression: cis-regulatory interactions at the MRF4/Myf-5 locus. Dev Biol, v.188, n.2, p.349-62, 1997.

ZACKS, S.I.; SHEFF, M.F.; SAITO, A. Structure and staining characteristics of myofiber external lamina. J Histochem Cytochem, v.21, n.8, p.703-714, 1973.

ZHANG, W.; BEHRINGER, R.R.; OLSON, E.N. Inactivation of the myogenic bHLH gene MRF4 results in up-regulation of myogenin and rib anomalies. Genes Dev, v.9, n.11, p.388$1399,1995$. 